\title{
Moral Character versus Situations: an Aristotelian contribution to the debate $^{1}$
}

Anna Marmodoro (University of Oxford)

In everyday life we assume substantial behavioural reliability in others, and on the basis of it we talk of people as acting "in character" and "out of character". This common assumption seems intuitively well founded. But recent experiments in social psychology have generated philosophical controversy around it. In the context of this debate, John Doris challenges Aristotle's well known and influential view that people's behavioural reliability with respect to acting virtuously is underpinned by character traits, understood as settled and integrated dispositions of the agent to have appropriate judgment and appropriate feelings toward what she is called upon to do in a given situation. In this paper I will take John Doris' challenge at face value, and argue in response that Aristotle's position is not undermined by it. In fact, rethinking Aristotle's realism about character and moral virtues in light of Doris' criticism has important and hitherto unexplored heuristic value for Aristotelian scholars and situationist philosophers alike.

\section{Introduction}

In everyday life we assume substantial behavioural reliability in others, and on the basis of it we talk of people as acting "in character" and "out of character". This common assumption seems well founded: if people weren't behaviourally reliable "we wouldn't

\footnotetext{
${ }^{1}$ Earlier versions of this paper were presented in Oxford (at the international conference Development of Character: The Aristotelian Tradition and Contemporary Developmental Psychology in Keeble College; and at the Centre for the Study of Greek and Roman Antiquity in Corpus Christi College) and in Cambridge (at the B-Club seminar in the Faculty of Classics). The author thanks the audiences for stimulating questions and discussion. The European Research Council and the British Academy have supported two different stages of the research leading to the preparation of this article.
} 
Journal of Ancient Philosophy Vol. V 2011 Issue 2

fare as well in social coordination as we do". ${ }^{2}$ How could we entrust a babysitter with our child? How could we expect fellow drivers to respect the rules of the road? How could we count on friends if need arises? Or, for that matter, how could friends count on us?

In recent years however philosophers and psychologists alike have probed this assumption. On the one hand there is an ongoing controversy on what would best explain such reliability, if it exists. One the other, some have put forward the radically different hypothesis that "most of [the] seeming order [in ordinary human behaviour] is a kind of cognitive illusion ... [H] uman beings are adept at seeing things as they believe them to be, at explaining away contradictions and, in particular, at perceiving people as more consistent than they really are."3

Aristotle, as is well known, is on the side of those who hold that people are behaviourally substantially reliable. In his ethical writings he develops a sophisticated theory to explain how behavioural reliability with respect to acting virtuously is underpinned by tendencies or dispositions of the agent to have appropriate judgement and appropriate feelings toward what she is called upon to do in a given situation. ${ }^{4}$ Such tendencies are developed through education and habituation, until they become settled states - ways of being for the moral agent.

Aristotle's view has been hugely influential in the subsequent history of philosophy, and was developed into what we nowadays call virtue ethics. But recent experiments in social psychology have generated philosophical controversy around it, and have been taken to lend support to an alternative view, known in the literature as situationism. On this view, what govern moral behaviour are the situations in which the

\footnotetext{
${ }^{2}$ Doris, John. Lack of Character (Cambridge University Press 2002) p. 65.

${ }^{3}$ Nisbett, R. E., \& Ross, L. Human Inference: Strategies and Shortcomings of Social Judgment (Englewood-Cliffs: Prentice-Hall 1980) pp. 7-8, my emphasis.

${ }^{4}$ By dispositions (hexeis) Aristotle means: "the things in virtue of which we stand well or badly with reference to the passions, e.g. with reference to anger we stand badly if we feel it violently or too weakly, and well if we feel it moderately; and similarly to the other passions." See Nicomachean Ethics, 1105b25-8. He further writes: "In respect of the excellences and the vices we are said ... to be disposed in a particular way" (1106a6). In what follows all quotes from Aristotle are from the Nicomachean Ethics unless otherwise specified.
} 
Journal of Ancient Philosophy Vol. V 2011 Issue 2

agent finds herself in, rather than her character: the same situation elicits the same behavioural response by a variety of supposedly different subjects; and additionally, one subject's supposedly consistent behaviour may change significantly because of a change in the situational variables. ${ }^{5}$ In the context of this debate, John Doris' critique of virtue ethics is particularly relevant to ancient philosophy scholarship because of its explicit connection with Aristotle's views.

In this paper I will take Doris' challenge at face value ${ }^{6}$ and argue in response that Aristotle's position is not undermined by it. In fact, rethinking Aristotle's realism about character and moral virtues in light of Doris' criticism has important and hitherto unexplored heuristic value for Aristotelian scholars and situationist philosophers alike which I will point to in the discussion that follows.

My contribution to the debate between virtue ethicists and situationists will be to introduce a conceptual distinction between different types of situational coefficients which make a difference to the agent's moral behaviour: I shall distinguish between reasons for action, and enablers of action. This distinction calls for a re-evaluation of the situationists' experimental findings. Secondly, following a lead offered by Aristotle in his analysis of incontinent behaviour, I will argue that there are cases in which one and the same situational factor can play different roles in determining the agent's behaviour: it may be a reason for action, or an enabler for action. Thus, it would be helpful to the advancement of the ongoing discussion if the situationist experimental psychologists could devise ways of testing how to discriminate which role a factor is playing for the agent in a given situation.

\footnotetext{
5 "Behavioral reliability ... is highly specific...Such contextualized predictability is arguably insufficient for trait attribution; if the reliability is highly contingent, perhaps it should be explained by reference to situational continuity alone rather than character traits." (Doris 2002: 65 , my emphasis)

${ }^{6}$ I will not engage, like others have done, with issues regarding the accuracy and reliability of the experiments, and with the further question of whether the experimental findings available to the situationists do allow for the generalized conclusions the situationists draws from them.
} 
Journal of Ancient Philosophy Vol. V 2011 Issue 2

On the other hand, from the situationists' experiments we learn how relevant the agent's physical and psychological well-being is to her ethical behaviour. Following this lead, my contribution to Aristotelian scholarship will be to show how Aristotle's theory of the external goods necessary to the achievement of virtue (and happiness) can be extended to accommodate the situationists' findings, and include not only circumstances and material means for virtuous behaviour, but also other elements pertaining to the agent's well-being.

\section{Character traits}

Both sides in the debate over the existence of character traits might be willing to adopt John Doris' following account: positing character traits is justified when character traits have a predictive and explanatory role to play in relation to behaviour; and when existence of character traits can be confirmed by empirical evidence. ${ }^{7}$

Additionally, Doris stipulates that character traits make up stable, consistent, and integrated characters - what he calls "global" characters. Thus, a global character is such that its constitutive traits are reliably manifested in trait-relevant behaviors "over iterated trials of similar trait-relevant eliciting conditions", but also "across a diversity of traitrelevant eliciting conditions, that may vary widely in their conduciveness to the manifestation of the trait in question". On this view a generous person will be act generously on any occasion that calls for generosity, albeit in varying circumstances: with friends, colleagues, strangers. But also "in a given [global] character, the occurrence of a trait with a particular evaluative valence is probabilistically related to the occurrence

\footnotetext{
7 "When a person has a robust trait, they can be confidently expected to display trait-relevant behavior across a wide variety of trait-relevant situations, even when some or all these situations are not optimally conducive to such behavior" (Doris 2002: 18). For the moment I will gloss over the qualification 'robust' that Doris gives to character traits so defined. I will return to it below in the section 'What, if not character traits?' where I address the distinction Doris draws between global (robust) and local caracther traits.
} 
Journal of Ancient Philosophy Vol. V 2011 Issue 2

of other traits with similar evaluative valences". ${ }^{8}$ In other words, we would reasonably expect a generous person to also be honest, courageous, etc. This is what makes the character "integrated".

Doris traces this realist view of character back to Aristotle. ${ }^{9}$ There appears to be no reason to contest this connection - at least for the sake of exploring its heuristic value. ${ }^{10}$ Aristotle talks about virtues (and vices) which in his view are acquired character traits; ${ }^{11}$ while Doris' globalist account of character includes more broadly innate as well acquired traits; but with this proviso, there is plenty of textual evidence that lends support to Doris' view that Aristotle held a globalist conception of character (as constituted by acquired moral traits).

In the Nicomachean Ethics for example Aristotle claims there that genuine virtuous action proceeds from "firm and unchanging character" (1105b1); virtue is a settled "state concerned with choice" (1106b36), "that sort of habit from which men have a tendency to do the best actions" (Eudemian Ethics, 1222a6). These statements read as positing that (virtuous) characters are stable and consistent, in line with Doris' description of global characters.

\footnotetext{
${ }^{8}$ Doris 2002: 22.

${ }^{9}$ Doris 2002: 23.

${ }^{10}$ One might argue, as for example Kamtekar has done, that "the character traits conceived of and debunked by situationist social psychological studies have very little to do with character as it is conceived of in traditional virtue ethics" (2004: 460). Or even more explicitly, that: "Although Harman and Doris take this conception of a character trait to be the same as Aristotle's, it is not". (2004: 467) See Kamtekar, Rachana "Situationism and Virtue Ethics on the Content of Moral Character", Ethics (2004), CXIV: 458-491. While I reckon that situationists like Doris have done little work to spell out a full-fledged account of what they take character traits to be; and that they have not provided themselves reasons and evidence why they think they are justified in ascribing a globalist conception of character to Aristotle, I think it is heuristically valuable to grant the situationists that Aristotle's realism is a form of globalism (albeit restricted to acquired moral character traits). The reasons will be discussed in the next sections of this essay.

${ }^{11}$ See 1105b20-1106a13.
} 
Journal of Ancient Philosophy Vol. V 2011 Issue 2

Additionally, Aristotle's well known claim concerning the unity of virtue may plausibly be read as aligned with Doris' point that character is "integrated": traits with the same valence go hand in hand as it were.

"It is not possible to be good in the strict sense without practical wisdom, nor to be practically wise without moral virtue. But in this way we may also refute the dialectical argument whereby it might be contended that the virtues exist in separation from each other; the same man, it might be said, is not best equipped by nature for all the virtues, so that he will have already acquired one when he has not yet acquired another. This is possible in respect of the natural virtues, but not in respect of those in respect of which a man is called without qualification good; for with the presence of the one quality, practical wisdom, will be given all the virtues." $(1144 \mathrm{~b} 32-1145 \mathrm{a} 2)^{12}$

For the sake of the present argument, let then the point be granted that Doris' account of a global character does latch on to Aristotle's realist conception of moral character traits. I turn now to the arguments that Doris and others have made against this conception of character.

Doris challenges globalist conceptions of character, including Aristotle's, on the ground that they are empirically inadequate. He writes:

"Four related observations tell against globalism ... (1) Low consistency correlations suggest that behavior is not typically ordered by robust traits. (2) The determinative impact of unobtrusive situational factors undermines attribution of robust traits. (3) The tenuous relationship found between personality measures and overt behavior leaves globalist accounts of human functioning empirically undersupported. (4) Biographical information often reveals remarkable personal disintegration ... Individually, each type of evidence is perhaps only suggestive, but

\footnotetext{
${ }^{12}$ Aristotle's argument for the unity of the moral virtues is that an agent cannot have some moral virtues and not others, because if she has some moral virtues, she must have practical wisdom; and if she has practical wisdom, she must have all the moral virtues. Aristotle's justification for this view is not relevant to the present discussion, but has been amply discussed in the literature. When giving this argument, Aristotle contrasts moral virtues with what he calls "natural virtues". For Aristotle's distinction between natural and moral virtues see Nicomachean Ethics 1144b1-17. Natural virtues are innate good qualities of temperament, which can lead their possessor astray unless they are guided by reason in the form of practical wisdom. For example a naturally kind disposition without the guidance of practical wisdom might motivate the agent to indulge others to their detriment, or to help the undeserving at the expense of the deserving, etc. The addition of practical wisdom turns a natural virtue into a true moral virtue, for example kind disposition into helpfulness.
} 
Journal of Ancient Philosophy Vol. V 2011 Issue 2

the collective import is unquestionably awkward for globalism". (2002: 64-65, my emphasis)

The second "observation" rests on recent studies in social psychology, and it is supposed to be the leverage point in Doris' argument against Aristotle. The social psychology studies in question draw on experiments mostly testing people's behavioural response to situations which call for a virtuous action, which is ultimately not performed by most of the subjects involved. ${ }^{13}$ The experiment's results are supposed to put pressure on globalist conceptions of character if read along these lines: if behaviour is typically ordered by global character traits, systematic observation will reveal behavioural consistency. But systematic observation does not reveal pervasive (that is, beyond chance) behavioural consistency. On the contrary (supposedly) 14 "unobtrusive situational factors" are observed to make a very significant difference to how an agent behaves. Thus, people lack character.

The experiments are very many, and for some of them different variants have been tried out. They have been described in detail in the literature. I will give here only an essential sketch of some key examples, ordered by the increasing triviality of the disturbance-factors involved.

Possibly the most infamous is Stanley Milgram's experiment at Yale University, set up as a study on memory and learning. The character trait of compassion is put to test. Subjects who had agreed to participate were instructed by the experimenter to administer "painful but not dangerous" electrical shocks, in fifteen-volt increments, to a co-

\footnotetext{
${ }^{13}$ For all experiments, it is assumed that the subjects who participated were ordinary characters with no pathology of any kind; with ordinary personal histories etc. It is further assumed that the group of subjects involved in each experiment included a variety of characters, and not only people with the same characteriological profile. These are necessary conditions for the results of the experiments to deliver reliable evidence. It is here assumed that the conditions are satisfied, although it is not clear that in all cases the experimenters acquired all the necessary information about the participants and that they did so in a reliable manner.

${ }^{14}$ I will address in the following sections of the essay the issue of whether the situational variants the experimenters test are as trivial and unobtrusive as they take them to be.
} 
Journal of Ancient Philosophy Vol. V 2011 Issue 2

participant (in fact a confederate of the experimenter) for incorrect answers or no answer at all to word-matching questions.

Sixty percent of the subjects involved in administering the electrical shocks continued to shock the confederate all the way up to the end of the scale (450 volts), while forty percent stopped between the 300-volt level (labeled "Extreme Intensity Shock") and the end of the scale.

In Milgram's experiment the (supposedly) trivial factor that made all the difference to the subjects' behaviour was declared to be the experimenter's academic authority over the subjects, who thought they were participating in a study of memory and learning processes.

Another much discussed experiment took place at the Princeton Theological Seminary. Students were asked to participate in a study on the vocational careers of the seminary pupils. As part of this study, they were told that they were to give a talk that would be recorded in the adjacent building. Some participants were told that they should hurry, since they were expected to have been at the venue for the talk a few minutes ago; others were told that they should go right over; others were told there were a few minutes to spare before they were expected. On their way to the next building, participants encountered a person (in fact a confederate of the experimenter) in apparent physical distress and in need of assistance.

No correlation was found between students' religious goals (explicitly stated before beginning the experiment) and whether they helped the person in need or not. But there was a strong correlation between the participants' offers to help and their beliefs about how much time they had before giving their talk. Sixty-three percent of those with a few minutes to spare, and forty percent of those who had been told to go right over helped; but of those who had been told they were already late only ten percent did.

In this context, the degree to which the students had been prompted to hurry is the (supposedly) trivial and contingent feature of the situation that determined the subjects' behaviour. 
Journal of Ancient Philosophy Vol. V 2011 Issue 2

On yet another experiment, participants were asked to make a telephone call from a public pay phone, in shopping centers in San Francisco and Philadelphia. Some subjects found a dime in the pay phone (planted there in advance by the experimenters); others did not. As each subject left the phone booth after the call, a confederate of the experimenter dropped a folder full of papers in his or her path. Over eighty-seven percent of the people who had found the dimes helped the confederate to pick up her papers; but only three percent of those who had not found a free dime did. What is striking in this last experiment is the apparent insignificance of what seems to make all the difference to the subject's display of helpfulness: finding a dime.

Doris takes these experiments (along with many others carried out with the same overall results) to show "not [just] that mood influences behavior . . . but just how unobtrusive the stimuli that induce the determinative moods can be." ${ }^{15}$ If so, Doris argues, the view that characters are stable, consistent, and integrated, is empirically falsified.

Doubts have been raised on the validity of the results of the experiments described above and on whether they provide adequate evidence for the general conclusions on character that Doris (and others) want to draw from them: the experiments involved only a small number of subjects; the subjects participating in each experiment were tested only once; etc. For the sake of argument, I here grant that the experiments above do deliver reliable results, because my goal is to explore their potential heuristic value.

\section{What, if not character traits?}

If there is a social phenomenon to be accounted for, namely that people do exhibit substantial behavioral reliability, what underpins it, if not clusters of robust and integrated character traits? In this section I will look into the alternative account Doris

\footnotetext{
${ }^{15}$ Doris 2002: 30.
} 
Journal of Ancient Philosophy Vol. V 2011 Issue 2

commends; by bringing out the difficulties that account is prey to, I aim to offer indirect support to globalism.

Doris' alternative to globalism is known in the literature as situationism. Supporters of this view emphasise the importance that context ought to be given in explaining behavior. They denounce the so called "overattribution error", that is to:

"inflate the importance of dispositions and neglect the importance of situations in explaining behavior." (2002: 93)

On this view, only situation-particular or local character traits are stable, and they typically govern behavior. This is the view that Doris explicitly endorses: ${ }^{16}$

"Local traits are likely to be extremely fine-grained; a person might be repeatedly helpful in iterated trials of the same situation and repeatedly unhelpful in iterated trials of another, surprisingly similar situation." (2002: 65)

E.g.

"Carol is extremely extroverted in one-on-one situations, is only moderately extroverted when in small groups, and is not at all extroverted in large groups. She will appear very comfortable and outgoing if you meet with her alone, but will clam up and appear very shy and awkward if you encounter her in a large group setting". (Kunda Z. Social Cognition: Making Sense of People (MIT University Press 1999) pp. 443-4

I take it that the last example suggests that the subject has three local character traits: sociability-in-one-on-one-relations; sociability-in-small-groups; and sociability-inlarge groups. But how are they individuated? Are they degrees of manifestation of the same quality, that is sociability? Do they relate to sociability as determinates to a determinable? As species to a common genus? Or how else?

By way of explanation, Doris merely contrasts local to global character traits. If Carol had the global trait of sociability, she would be extroverted in all sorts of situations, including those that facilitate it the least. But on the basis of this only, it is hard to get a grip on the difference between globalism and situationism. In fact, if we are meant to understand global character as a cluster of traits which are supposed not to admit degrees

\footnotetext{
${ }^{16}$ Notwithstanding occasional expressions in his writings of a much more radical, elimininativist view. See below p. 13.
} 
Journal of Ancient Philosophy Vol. V 2011 Issue 2

of manifestation and different ways of being embodied, then what Doris is criticising is a view that actually nobody holds.

The thesis on which it is plausible to claim that there is clear divergence between globalism and situationism concerns the integration of character traits (whether they are individuated in a coarse- or fine-grained way). Integrated character traits make up distinctive characters, on the globalist view. But character for Doris is, on the contrary, typically fragmented:

"If human personality were typically structured as evaluatively integrated associations of robust traits, it should be possible to observe very substantial consistency in behavior. I therefore contend personality should be conceived of as fragmented: an evaluatively disintegrated association of situation-specific local traits." (2002: 64)

Doris' argument is that integration of character traits is not empirically observable; hence we have no justification in postulating it. But this conclusion is too quickly drawn.

Doris' antirealist contention about integration of character parallels, mutatis mutandis, Hume's claims about causation. According to Hume, there is no necessary connection between cause and effect but only regular succession, because we do not observe this connection. ${ }^{17}$ On Doris' account of character, there is no integral connection between an agent's character traits, because we don't have empirical evidence for it; thus, all there is to character is aggregation of (local) traits. Doris' argument to the effect that character traits are not integrated is along the same lines as Hume's; the conclusion is derived on the basis of a methodological principle they endorse: empiricism. But how can there be empirical evidence for the necessary connection between com-present phenomena? One can observe only the compresence, not the connection. ${ }^{18}$

Doris' overall conclusion is that "people typically lack character" (2002: 2). I take the claim to mean that people typically lack integrated character; not that they lack

\footnotetext{
${ }^{17}$ A Treatise of Human Nature, edited by L. A. Selby-Bigge, 2nd ed. revised by P.H. Nidditch, Oxford: Clarendon Press, 1975) pp. 165 and 662.

${ }^{18}$ Additionally, Doris' argument from lack of empirical evidence would not bear on Aristotle. For, Aristotle justifies the unity of virtues thesis with an a priori argument from the unity of the good, on which I touched upon earlier, pp. 5-6.
} 
Journal of Ancient Philosophy Vol. V 2011 Issue 2

character traits altogether. Situationists do sometimes express themselves as if they held a stronger view; that is, eliminativism concerning the very existence of character traits (and not only their global aspect). Doris himself appears at times to endorse an eliminativist stance, e.g.:

"Behavioral reliability ...is highly specific...Such contextualized predictability is arguably insufficient for trait attribution; if the reliability is highly contingent, perhaps it should be explained by reference to situational continuity alone rather than character traits." (2002: 65, my emphasis) ${ }^{19}$

But is eliminativism a viable alternative to globalism? How much does an eliminativist need to build into a situation to make situations explanatory sufficient? How would the eliminativist explain two people's different reactions to the very same situation? The eliminativist position has not so far been articulated in a way that can address these questions - if it can address them, it is up to the eliminativist to show it.

In conclusion, in this section I have offered indirect support to globalism by arguing that the proposed alternatives are prey to significant difficulties. In the next section I will examine some of the replies that Aristotelian scholars have provided to address Doris' arguments. In the final section, I will propose my own line of response.

(Aristotelian) Ways of addressing Doris' challenge $e^{20}$

There is some consensus among Aristotelian scholars on what I call the "bitingthe-bullet reply" to Doris' challenge.

Rachana Kamtekar ${ }^{21}$ for example, commenting on the outcome of the Princeton Theological seminary experiment, writes:

\footnotetext{
${ }^{19}$ See also e.g. Harman: "It seems that ordinary attributions of character traits to people are often deeply misguided and it may even be the case that there is no such thing as character, no ordinary character traits of the sort people think there are, none of the usual moral virtues and vices" (1999: 316).

${ }^{20}$ The following discussion does not aim at being exhaustive, but only at giving the reader a feel for some of the most recent arguments that have been put forward in defence of Aristotle.
} 
Journal of Ancient Philosophy Vol. V 2011 Issue 2

"The absence of widespread consistency in helping behavior is just what virtue ethics would predict" (2004: 466)

And then generalizes the point thus:

“Even our lay understanding of character doesn't ordinarily lead us to expect that someone whom we may legitimately call helpful will display actions of the helpful type (whatever that type of action is) on every occasion, and so we wouldn't conclude from one failure to help that a person lacks the character trait of helpfulness". (2004: 475)

In support of this biting-the-bullet line of response to the situationists findings, Kristján Kristjánsson ${ }^{22}$ draws attention to the fact that Aristotle sets up a complex path of moral education. Presumably Kristjánsson assumes that the complexity of the path is such that it excludes most people from completing their moral training. Hence, by making so difficult to learn to be virtuous Aristotle implicitly admits that very few of us can be expected to achieve moral goodness. Kristjánsson argues thus:

"In the Nicomachean Ethics, Aristotle proposes a complicated ... stage theory of moral development, ranging from the level of 'the many' ... through the levels of 'the soft', 'the resistant', 'the incontinent' and 'the continent', to that of the 'fully virtuous'. Aristotle forthrightly acknowledges in a couple of places that 'most people' are placed between the levels of the incontinent and the continent ... [M]ost people cannot be counted upon to respond virtuously in morally tricky situations, for only a small minority has reached the level of full virtue. Far from being a reductio of Aristotelian characterological explanations, the results of the psychological experiment turn out to be exactly what coherent Aristotelians would expect." (2008: 66)

But this line of response is clearly inadequate to explain the actual figures resulting from the experiments. For example, in Milgram's original experiments, pre-experiment predictions were that only zero to three percent of the participants would go all the way in administrating an electric shock to the other experiment's participant. But in fact (see above p. 8) sixty percent of the participants went to the end of the scale (450 volts), while forty percent stopped between 300 volts (labeled "Extreme Intensity Shock") and the

\footnotetext{
${ }^{21}$ Kamtekar has also other strands of argument in response to situationism; I am drawing here only on the line of argument that a number of other scholars share in.

${ }^{22}$ Kristjánsson, K. "An Aristotelian Critique of Situationism”, Philosophy (2008) LXXXIII: 5576
} 
Journal of Ancient Philosophy Vol. V 2011 Issue 2

end. ${ }^{23}$ Is this explained, according to Aristotle, by the admission that most of us find being virtuous a difficult thing to learn?

Aristotle does say that:

"It is not easy task to be good. For in everything it is not easy task to find the middle, e.g. to find the middle of a circle is not for everyone but for him who knows; so, too, any one can get angry - that is easy - or give or spend money; but to do this to the right person, to the right extent, at the right time, with the right aim, and in the right way, that is not for everyone, nor is it easy; that is why goodness is both rare and laudable and noble." (1109a25-29)

But from such a claim it would seem and exaggeration to conclude that Aristotle would think there is nothing to be surprised about in the outcome of experiments such as Milgram's.

Nancy Snow ${ }^{24}$ tries a fresh start in the debate between Aristotelian virtue ethicists and situationists. She draws attention to the fact that

"Virtues are complex constellations of cognitive, motivational, and affective elements ... The constituent elements of a virtue must fit together ... for it to be a virtue in the traditional Aristotelian sense." $(2010: 86)^{25}$

The Nicomachean Ethics provides plenty of evidence that this is indeed Aristotle's view, e.g.:

"Moral excellence is a state concerned with choice, and choice is deliberate desire, therefore both the reasoning must be true and the desire right, if the choice is to be good, and the latter must pursue just what the former asserts" (1139a22-25)

"For to such persons, as to the incontinent, knowledge brings no profit; but to those who desire and act in accordance with a rational principle knowledge about such matters will be of great profit" (1095a8-11)

But, making a departure from the traditional interpretation of Aristotle's position, Snow takes virtuous behaviour to be a cognitive-affective response to the environment

\footnotetext{
${ }^{23}$ I endorse Harman's comment: "Can we really attribute a 2 to 1 majority response to a character defect? And what about the fact that all subjects were willing to go at least to the 300-volt level? Does everyone have this character defect?" (1999: 322).

${ }^{24}$ Snow, Nancy. Virtue as Social Intelligence (Routledge 2010).

${ }^{25}$ See also: "Virtues are well-integrated bundles or configurations of motivations, cognitions, and affective sensitivities in which the motivations characteristic of specific virtues shape and influence the other elements" (2010: 87).
} 
Journal of Ancient Philosophy Vol. V 2011 Issue 2

determined by how the subject interprets the situation from her unique, point of view. People interpret the (external or internal) stimuli they respond to - Snow says; they give them subjective meaning. (2010: $3 ; 13,17,18,19,21)$. This is the key tenet in her response to situationism: to test whether people have or not an enduring character trait of the Aristotelian kind, experimenters ought to compare situations that have similar meanings for the participants; but they don't - thus they are not testing for Aristotelian virtues.

Snow's line of response is however based on presuppositions that conflict with fundamental commitments of Aristotle's, and is thus not an available option for an Aristotelian. Snow draws a contrast between objective features of a situation in which moral action is required and the meaningfulness of the situation for the subject involved in it; and she additionally assumes that the meaningfulness of the situation is not observable - it is not accessible to anyone else but the subject. This assumption in implicit in her debate with the situationists:

"The situations in which behaviour was studied were described solely in objective terms, that is, in terms that were accessible to observers ... and not in terms of the meanings that the physical situations had for subjects" (2010: 3; see also 18).

But if the meaning of a situation for a subject is unobservable by a third party, moral education is hardly possible; this is in sharp contrast to Aristotle's views.

For Aristotle the perfectly good moral agent is the model everyone should strive to imitate, for:

"The good is an object of wish, but for each person the apparent good; ...that which is in truth an object of wish is an object of wish to the good man, while any chance thing may be so to the bad man, as in the case of bodies also the things that are in truth wholesome are wholesome for bodies which are in good condition, while for those that are diseased other things are wholesome - or bitter or sweet or hot or heavy and so on; since the good man judges each class of things rightly, and in each the truth appears to him ... For each state of character has its own ideas of the noble and the pleasant, and perhaps the good man differs from others most by 
Journal of Ancient Philosophy Vol. V 2011 Issue 2

seeing the truth in each class of things, being as it were the norm and measure of them." (1113a24-34, my emphasis) ${ }^{26}$

But if others cannot "observe" the meaning of a situation for the perfectly good moral agent, if no one else has access to the meaning of the situation apart from the subject involved, there cannot be either teachers or learners of virtue. Thus, an Aristotelian cannot embrace the consequences that follow from Snow's reply to the situationists.

The heuristic value of Doris' challenge

I turn now to explore the heuristic value of the situationist challenge. In this section I will argue that it does not undermine Aristotle's position; but rethinking Aristotle's realism about moral character in light of Doris' criticisms has important and hitherto unexplored heuristic value for Aristotelian scholarship, and for situationist philosophers alike.

Two different types of factor

My first contention is that the experiments that cognitive psychologists perform to test for moral traits and character do not acknowledge the difference between two types of coefficient operative in the situation of a moral agent. On the one hand, the experiments test for the effect of such factors as being late in giving a talk, or one's readiness to help a person in need; on the other hand, they test for the effect of such factors as the agent being pleased to find a dime in a phone booth. I submit that these factors fall into different types, and that their role in the performance of virtuous actions is fundamentally different; in consequence, what they show about moral traits is different as well.

\footnotetext{
${ }^{26}$ See also: "There is a mark to which the man who possesses reason looks, and heightens or relaxes his activity accordingly, and there is a standard which determines the mean states which we say are intermediate between excesses and defect, being in accordance with right reason." (1138b21-25).
} 
Journal of Ancient Philosophy Vol. V 2011 Issue 2

The one type of coefficient are reasons for action (or inaction); the other I shall call enablers (and disablers) of action. This distinction calls for a re-evaluation of the situationists' experimental findings. Being late in giving a talk is for example a reason why someone might decide against stopping to help a person in need; and finding a dime (and the agent consequently finding herself in a good mood) is a psychological enabler of helping behaviour toward someone in need. In the case of Milgram's experiments, the authority of the psychologist is a reason why the subjects followed the experimenter's promptings; there are also disablers in play, preventing the manifestation of compassion: the unpreparedness of the experiment's subjects, the relentless pressure exerted on them by the experimenter, the fast pace of the experiment, the stepwise, slippery slope nature of the subjects' decisions (each increase of the electric shock was by 15 volts), etc. The enabler/disablers category can be fairly broad and varied, and include the empirical findings of further experiments, e.g. that show that we are much more likely to help others when we find ourselves in pleasant weather conditions; in the absence of unpleasant noises; when we have familiarity with a potential victim; when we are in a group, etc.

For all the cases in which the experimental set up provides a reason for the agent not to perform the virtuous action in question in the circumstances, e.g. lateness in giving a talk, or the authority of a scientist, such reasons do in fact fall within the scope of the moral agent's deliberation (whether she does in fact deliberate or not in the given circumstances). Thus, these cases are not a challenge to Aristotle's realism about moral character, for Aristotle provides in his ethics a very sophisticated account of moral deliberation. ${ }^{27}$ His paradigmatic definition of virtue in the Nicomachean Ethics gives a pivotal role to our faculty of reasoning:

\footnotetext{
${ }^{27}$ Annas for example: "A virtue is a disposition to act on reasons. It is exercised in making decisions and is built up not by mindless habit but by and in deliberating and making decisions ... The more you develop a virtue, the less important to you is mere habit, and the more complex and flexible your ability to reason about new and innovative kinds of situation you may be faced with. Hence, the more virtuous you are, the more complex and dynamic your character". (2005: 637)
} 
Journal of Ancient Philosophy Vol. V 2011 Issue 2

"Virtue, then, is a state that decides, consisting in a mean, the mean relative to us, which is defined by reference to reason, that is to say, to the reason by reference to which the prudent person would define it." (1107a2-3, my emphasis)

A second issue to examine is whether the reasons for action in play in the situationists' experiments are actually trivial as the situationists present them to us. In so far as the situationist challenge is directed against Aristotle's own account of virtuous behaviour, it fails to take into account some of the defining tenets of Aristotle's position: Aristotle maintains that there can be no rule, however complex, that can codify the wisdom required for sound ethical judgment, because (in Wiggins' paraphrase of the opening of the second book of the Nicomachean Ethics),

"The subject matter of action (the province where it operates and field of things it is concerned with) is inexhaustibly indefinite" 28

This means that for Aristotle, unless the experimenters ask the subjects for their own appreciation of the situation, they cannot know what importance such factors as being late to one's lecture has for the subject. ${ }^{29}$ On what ground then does the experimenter select certain factors in a given situation as supposedly trivial?

As we have seen above (p. 16), Aristotle does hold that one can take as a point of reference for virtuous action in a given situation what the excellent moral agent would do in that situation (see NE 1107a2-3). But this does not mean that every moral agent would be called upon to do the very same in a given situation; e.g. the courageous way to respond to a threat will vary if the agent is a frail old man or a soldier. Each agent's

\footnotetext{
${ }^{28}$ This is Wiggins' (2004: 480-1) paraphrase of of Aristotle's Nichomachean Ethics (1104a1-5): "The whole account of matters of conduct must be given in outline and not precisely, as we said at the beginning that the accounts we deman must be in accordance with the subject-matter. Matters concerned with conducts and questions of what is good for us have no fixity, any more than matters of health."

${ }^{29}$ See e.g. Kamtekar: "The experiments appealed to by situationists for the most part assume that subjects share the experimenter's construal of the situation." (2004: 470, my emphasis); "There would seem to be a wealth of information about subjects' feelings about their actions that goes unmentioned in situationist conclusions - this even though a number of studies record subjects' postexperiment reflections on what they did." (2004: 473)
} 
Journal of Ancient Philosophy Vol. V 2011 Issue 2

circumstances vary, objectively, and accordingly the importance of a situational variable in a given situation varies too. Aristotle writes:

"The account of particular cases is yet more lacking in exactness; for they do not fall under any set of precepts, but the agents themselves must in each case consider what is appropriate to the occasion." (1104a1-9)

This was not taken into account by the situationist experimenters/philosophers, by evaluating how trivial a situational factor is for the agent. If this is not taken into account in analysing the action of the subject in an experiment, the only other way the experimenters can justify their stance in evaluating the importance (or triviality) of certain situational factors for the subject is by calling into question Aristotle's particularist foundations of his ethics. ${ }^{30}$ There are no arguments to this effect in Doris, and in the situationist literature more generally.

Further even if one granted the situationist that there is a category of situational factors that would count as trivial for any moral agent (notwithstanding their particular circumstances), would any trivial factor within that category produce the same experimental results; or is there something special about the 'trivial' factors selected by the situationists? How does the situationist experimenter choose to evaluate the situational variables in play in the experiments?

The second type of factor in play in the experiments the situationists rely on for their conclusions against globalism (and Aristotle), is not concerned with reasons for action in the circumstances in question. For example, whether a subject has just had a delicious cake before being confronted with situations calling for a moral action, or she is hungry, or restless (or has found a dime in a phone booth) are not factors that will enter the subject's deliberation as to whether e.g. assist the person in need or not. Nevertheless, the situationists do show with their experiments that these factors make a difference to the moral behaviour of the subjects. I group these factors under the category of enablers/disablers of virtuous activity.

\footnotetext{
${ }^{30}$ For a particularist interpretation of Aristotle's ethics, see e.g. Nussbaum Love's Knowledge (1990: 68) and The Fragility of Goodnesss (1986 : 299); Dancy Moral Reasons (1993: 50); McDowell "Comments on T. H. Irwin 'Some rational aspects of incontinence"” (1989: 94).
} 
Journal of Ancient Philosophy Vol. V 2011 Issue 2

These are factors that Aristotle does not identify in his analysis of virtuous behaviour. Does the experimental evidence now available show that Aristotle's account is in this respect inadequate? I wish to claim that it does not, because Aristotle can accommodate these factors into his analysis of virtue. I submit these factors can be thought of as a subset of the external goods that according to Aristotle (and in contrast with Socrates) are needed for the conduct of virtuous activity.

Aristotle acknowledges the importance of external goods in relation to moral conduct in clear terms in the Nicomachean Ethics:

"Yet evidently, as we said, it [i.e. happiness] needs the external goods as well; for it is impossible, or not easy, to do noble acts without the proper equipment. In many actions we use friends and riches and political power as instruments; and there are some things the lack of which takes the lustre from blessedness, as good birth, goodly children, beauty; for the man who is very ugly in appearance or ill-born or solitary and childless is hardly happy, and perhaps a man would be still less likely if he had thoroughly bad children or friends or had lost good children or friends by death." (1099a32-b9)

The factors Aristotle mentions in his own analysis of external goods are different from the ones the situationist experiments draw our attention to (such as e.g. having found a dime or having had a delicious cake before encountering a situation with moral demands on the subject). The latter are - to use John Cooper's categorization - neither "context providers" nor "instrumental means to the ends aimed at in virtuous activities". 31 Rather, they are "goods" that affect the agent's complex psychological equilibrium of dispositions, even if they don't register in the agent's awareness. Yet they are there, having their effect and influencing moral behaviour - as we are discovering via the situationists' experiments.

While we have come to realise the importance of these factors only thanks to experimental findings that weren't available to Aristotle, I see no difficulty in taking components of the physical or emotional condition or constitution of the agent (which are factors that the situationists' experiments show play a role in enabling or inhibiting the

${ }^{31}$ Cooper (1985: 183-184). 
Journal of Ancient Philosophy Vol. V 2011 Issue 2

disposition of the agent to carry out virtuous actions) as an extension of Aristotle's account of external goods.

Virtue is an activity of the soul. The soul is a connected set of capacities, including those of the biological constitution of an organism. There is the nutritive soul (which is responsible for growth and reproduction), the locomotive soul (for motion), the perceptive soul (for perception), and - in the case of humans only - the rational soul. As we know from the Function Argument in Nicomachean Ethics I 7, Aristotle grounds his account of virtue on the abilities of the agent's nature. Human beings are the only species in nature that have rational soul in addition to lower biological capacities shared with other living beings. Hence the distinctive and unique function of a human being consists in activity of the soul in accordance with a rational principle, and in the cases of a good moral agent, in accordance with virtue.

Virtue for Aristotle is the excellent activity of our whole being in accordance with reason. Hence, the mean in action and emotional response to a situation is for him to be shaped by the realities of the human psychological constitution. Thus the importance of the situational factors in play in any given context is not determined exclusively by rationality. ${ }^{32}$ There are biological conditions, and there may be psychological ones, as well, whose weight cannot be determined by rationality, or at least not always fully modified by it. Aristotle would therefore be ready to embrace the findings of biologists and the situationist psychologists, and accommodate them into his theory of virtuous behaviour.

In conclusion, there are two different responses to be given on behalf of Aristotle to the findings of the situationist experiments on virtuous behaviour. The situational

\footnotetext{
32 "Happiness is an activity of soul in accordance with excellence" (1102a5) ... "One element of the soul is irrational and one has a rational principle" (a26) ... "The irrational element also appears to be two-fold. For the vegetative element in no ways shares with reason, but the appetitive and in general the desiring element in a sense shares in it, in so far as it listens to it and obeys it." (1102b29-3)
} 
Journal of Ancient Philosophy Vol. V 2011 Issue 2

variables in the experiments are of two different types. Those that are reasons for action (or inaction) can be handled through Aristotle's theory of practical deliberation. Additionally, the interference of supposedly trivial reasons is to be reassessed in light of Aristotle's moral particularism. Secondly, the situational factors, whether internal or external factors, call for Aristotle's theory of the role of external goods to be expanded into a theory of enablers/disablers of virtuous activity. Thus the situationist challenge does not undermine Aristotle's realism about moral character; rather it enriches our understanding of it.

One factor with two roles

In the light of the conceptual distinction introduced here between reasons for action and enablers of action, I will now turn to examine cases in which one and the same situational factor can play both roles in relation to the agent's behaviour: it may be a reason for action, and an enabler for action. It is Aristotle's analysis of incontinence that introduces this further dimension, to be investigated experimentally and philosophically.

In the presence of bodily desires, e.g. for what is sweet, Aristotle describes action as resulting from the process of deliberation as follows:

"The one opinion is universal, the other is concerned with the particular facts ... when a single opinion results from the two, ... the soul must ... immediately act (e.g. if everything sweet ought to be tasted, and this is sweet, ... the man who can act and is not prevented must at the same time actually act accordingly)." (1147a25-28)

When the agent who feels desire for sweet things is presented with something sweet, the thought that sweets things are to be tasted and the thought that there is a sweet thing available come together in the process of deliberation of the agent; and the agent is led by desire to reach out for the sweet. The desire here acts as a reason for action.

But the incontinent may also be led to action in a different way; for, Aristotle says, desire can move directly bodily parts of the agent. Following on the text quoted above, we read: 
Journal of Ancient Philosophy Vol. V 2011 Issue 2

"When, then, the universal opinion is present in us forbidding us to taste, and there is also the opinion that everything sweet is pleasant, and that this is sweet (now this is the opinion that is active), and when appetite happens to be present in us, the one opinion bids us avoid the object, but appetite leads us towards it (for it can move each of our bodily parts); so that it turns out that a man behaves incontinently ..." (1047a31-b1, my emphasis)

The incontinent agent is aware that she should not eat the sweet, but she is aware of it in the way that a drunken person is aware of Empedocles' verses ineffectually without comprehending them. (See 1147b12 and 1047a18-23). In this case, the action of the agent does not follow deliberation, which would be based on reasons for action. Rather, desire bypasses the deliberative process in the agent, and leads the incontinent person to eat the sweet thing. Desire does not fight and win as a reason against reasons such as the harmfulness of excessive sweets. Rather, desire finds a way to directly move the bodily parts independently of the deliberative process, and in this situation functions as an enabler of action.

In sum, in the present case of incontinence, desire figures as a (non-winning) reason for action in the deliberative process of the agent; and desire is the enabler of the incontinent action, moving the bodily parts, despite the deliberative process. So, one and the same factor has both roles in the present situation.

The criterion I propose to distinguish between the two roles is that a situational factor is a reason for action if it can enter as a coefficient into the deliberation for action; it is an enabler or a disabler of action, not by entering into the deliberation, but by interfering positively or negatively with the realisation of the agent's action.

Thus, Aristotle's account of incontinence points the way towards an interesting advancement in situationist experimentation. Psychologists could devise ways of testing how to discriminate which role(s) a factor is playing in a given situation - as a reason and/or as an enabler. 
Journal of Ancient Philosophy Vol. V 2011 Issue 2

\section{Bibliography}

Annas, Julia. "Comments on John Doris's Lack of Character", Philosophy and Phenomenological Research LXXI (3) 2005: 636-642.

Cooper, John. "Aristotle on the Goods of Fortune", The Philosophical Review XCIV (2) 1985: 173-196

Dancy, Jonathan. Moral Reasons, Blackwell Publishing, 1993.

Doris, John. Lack of Character, Cambridge University Press, 2002.

Harman, Gilbert. "Moral Psychology Meets Social Psychology", Proceedings of the Aristotelian Society, XCIX 1999, pp. 315-31

Hume, David. A Treatise of Human Nature, edited by L. A. Selby-Bigge, 2nd ed. revised by P.H. Nidditch, Oxford: Clarendon Press, 1975.

Isen, Alice M. and Levin, Paula F. "Effect of Feeling Good on Helping: Cookies and Kindness", Journal of Personality and Social Psychology 21 1972: 384-88.

Kamtekar, Rachana "Situationism and Virtue Ethics on the Content of Moral Character", Ethics, CXIV 2004: 458-491.

Kristjánsson, Kristján. “An Aristotelian Critique of Situationism”, Philosophy LXXXIII 2008: $55-76$

Kunda Z. Social Cognition: Making Sense of People, MIT University Press, 1999.

McDowell, John. "Comments on T.H. Irwin's 'Some Rational Aspects of Incontinence”, Southern Journal of Philosophy 27 1989: 89-102.

Milgram, Stanley. "Behavioral Study of Obedience", Journal of Abnormal and Social Psychology 67 1963: 371-78.

Milgram, Stanley. Obedience to Authority, New York: Harper \& Row, 1974.

Nisbett, R. E., \& Ross, L. Human Inference: Strategies and Shortcomings of Social Judgment, Englewood-Cliffs: Prentice-Hall, 1980.

Nussbaum, Martha C. Love's Knowledge. Essays on Philosophy and Literature, Oxford University Press, 1990.

Nussbaum, Martha C. The Fragility of Goodness. Luck and Ethics in Greek Tragedy and Philosophy, Cambridge University Press, 1986.

Snow, Nancy. Virtue as Social Intelligence, Routledge, 2010.

Wiggins, David. 'Neo-Aristotelina Reflections on Justice', Mind 113 (451), 2004: 477 512. 